\title{
Degradation of Methylene Blue Using Synthesized Nanostructured CuO with High Specific Surface Area through Catalytic Oxidation
}

\author{
Amine El Farrouji ${ }^{1}$, Abderrahim Chihab Eddine ${ }^{1}$, Soumaya Elamal Bouzit ${ }^{2,3}$, \\ Brahim Boualy ${ }^{4}$, Ahmad Mehdi $^{5}$, Larbi El Firdoussi ${ }^{3^{*}}$ and Mustapha Ait Ali ${ }^{3}$
}

${ }^{1}$ Département de Chimie, Laboratoire Biotechnologie et Valorisation des Ressources Naturelles, Faculté des Sciences Ibn Zohr, Agadir, Morocco.

${ }^{2}$ Département de Physique, Laboratoire de Physique du Solide et des Couches Minces, Université Cadi Ayyad, Faculté des Sciences Semlalia Marrakech Morocco.

${ }^{3}$ Département de Chimie, Laboratoire Chimie de Coordination et Catalyse, Faculté des Sciences

Semlalia, Marrakech, Morocco.

${ }^{4}$ Département de Chimie, Laboratoire de Chimie et Modélisation Mathématique, Université Hassan 1er, Faculté Polydisciplinaire de Khouribga, B.P. 145, 25000 Khouribga, Morocco. ${ }^{5}$ Département de Chimie Moléculaire et Macromoléculaire, Institut Charles Gerhardt Montpellier, UMR 5253, Chimie Moléculaire et Organisation du Solide, Université Montpellier. Place E. Bataillon, 34095 Montpellier Cedex 5, France.

Authors' contributions

This work was carried out in collaboration between all authors. All authors read and approved the final manuscript.

Article Information

DOI: $10.9734 / I R J P A C / 2015 / 18057$ Editor(s):

(1) Sung Cheal Moon, Korea Institute of Materials Science (KIMS), Industrial Technology Support Division, Changwon, Republic of Korea. Reviewers:

(1) Imtiaz Ahmad, Institute of Chemical Sciences, University of Peshawar, Pakistan. (2) Anonymous, South Korea. Complete Peer review History: http://www.sciencedomain.org/review-history.php?iid=1052\&id=7\&aid=9548

\section{ABSTRACT}

Nanostructured $\mathrm{CuO}$ (CuO Nst) with specific surface area of $144.473 \mathrm{~m}^{2} / \mathrm{g}$ has been successfully synthesized via a facile solution-phase method at room temperature. As prepared CuO was characterized using x-ray diffraction (XRD), Brunauer-Emmett-Teller (BET) and transmission 
electron microscopy (TEM). The synthesized $\mathrm{CuO}$ was demonstrated as efficient and re-used catalyst in degradation of methylene blue in the presence of sodium hypochlorite through catalytic oxidation. More than $95 \%$ of the methylene blue was degraded after 30 min. After 5 successive catalytic cycles, the as-prepared $\mathrm{CuO}$ still remained its original catalytic activity, exhibiting good reusability and durability.

Keywords: Methylene blue; degradation; nanocrystalline copper (II) oxide; current efficiency; reusability.

\section{INTRODUCTION}

Colored wastewater from different industries affects the ecosystem in many ways. With the environmental regulations which become more and more stringent in recent years, how to eliminate hazardous materials (especially those highly toxic and carcinogenic contaminants) from wastewater and prevent them from entering environmental system is a focus of international concern [1].

A variety of physical, chemical, and biological methods have been applied for the treatment of wastewater, which contains dyes and heavy metals. Some methods such as catalytic reduction [2], photocatalysis [3], electrochemical oxidation [4], adsorption [5], and advanced oxidation [6], have been proven as practical methods for removing methylene blue (MB) from solutions. Therefore, in the course of this last decade, considerable interest has been paid to the oxidation processes, in which the highly reactive hydroxyl radicals $\left({ }^{\circ} \mathrm{OH}\right)$ are generated and cause the oxidative degradation of organics [7]. Among these, copper oxide (CuO) has gained increasing attention because of its low cost, non-toxic nature and high efficiency. It has been studied as a p-type semiconductor material (band gap $=1.2 \mathrm{eV}$ ) with distinctive properties, which makes it suitable for applications in many important fields of science and technology. However, for these applications, the size, morphology and specific surface area of the $\mathrm{CuO}$ particles are very important and sometimes, are strongly dependent on the preparation methods. Hence, powdery nanocatalysts are very likely to aggregate during the catalytic reaction owing to their high surface energy, which will significantly decrease their catalytic activity and reduce their lifetime. A lots of well-defined $\mathrm{CuO}$ nanostructure have been prepared, such as nanoparticles [8], nanosheets [9], nanorings [10], nanowhiskers[11], nanotubes [12], nanoleaves [13] and nanoflowers [14]. They have been made by a variety of synthetic routes, including thermal decomposition [15], sol-gel
[16], sonochemical [17], microwave irradiation [18], hydrothermal [19], precipitation [20], pyrolysis [21], electrochemical approaches [22] and mechanical milling methods [23]. All these methods require high temperature, inert atmosphere and long reaction time.

The current work is devoted to the synthesis of nanostructured $\mathrm{CuO}$ (CuO Nst) with high specific surface area using a fast, facile and inexpensive solution method which should be suitable for large-scale production. The synthesis was realized at room temperature from commercially available copper (II) sulfate pentahydrate $\left(\mathrm{CuSO}_{4}, 5 \mathrm{H}_{2} \mathrm{O}\right)$ and sodium dodecyl sulfate (SDS) as surfactant agent. Oxidative degradation of $\mathrm{MB}$ is applied as a model reaction to test the catalytic performance of the as-prepared $\mathrm{CuO}$ nanostructures.

\section{MATERIALS AND METHODS}

\subsection{Materials}

$\mathrm{CuSO}_{4} \cdot 5 \mathrm{H}_{2} \mathrm{O}$, methylene blue (MB), sodium dodecyl sulfate (SDS), aqueous $\mathrm{NaOCl}$ solution $(12 \%), \mathrm{NaOH}$ and ethanol were purchased from Sigma-Aldrich. All of those reagents were of analytic grade and used as received without further purification. Distilled water was used throughout the experiments.

\subsection{Preparation of the $\mathrm{CuO}$ Nanostructures}

The typical reaction process for the synthesis of nanostructured $\mathrm{CuO}$ was as follows. Firstly, $1 \mathrm{~g}$ $(4,01 \mathrm{mmol})$ of $\mathrm{CuSO}_{4} \cdot 5 \mathrm{H}_{2} \mathrm{O}$ and $0,2 \mathrm{~g}(0,62$ $\mathrm{mmol}$ ) of SDS were dissolved in $30 \mathrm{~mL}$ of distilled water. To the obtained bleu suspension, $20 \mathrm{~mL}$ of aqueous $\mathrm{NaOCl}$ solution (12\%) was added and the solution was stirred vigorously at room temperature for 5 minutes. The mixture turns immediately to a black suspension with addition of $20 \mathrm{~mL}$ of aqueous $\mathrm{NaOH}$ solution $(0,3 \mathrm{M})$ and stirring was continued for $10 \mathrm{~min}$. 
The final black suspension was filtered and washed several times with water and finally with ethanol. The product was dried in air at $100^{\circ} \mathrm{C}$ for $24 \mathrm{~h}$. This process can be simply scaled up for mass production.

\subsection{Characterizations}

The crystallographic information and chemical composition of the synthesized nonostructured $\mathrm{CuO}$ were established by X-ray diffraction patterns (XRD) using a Philips X'Pert MPD diffractometer with $\mathrm{Cu}$ Ka radiation $(\lambda=1.54178$ $\AA$ ). Transmission Electron Microscopy (TEM) observations were carried out at $100 \mathrm{kV}$ (JEOL 1200 EXII). Samples for TEM measurements were prepared by embedding the hybrid material in AGAR 100 resin, followed by ultramicrotomy techniques and deposition on copper grids. The specific surface area was obtained by BET on a Micromeritics Tristar 3000 after one night vacuum $(10-2 \mathrm{mbar})$ at $120^{\circ} \mathrm{C}$. The average pore diameter and pore volume were calculated by the barrett-Joyner-Halenda (BJH) method.

\subsection{Methylene Blue Degradation}

Commercial Methylene blue $\left(\mathrm{C}_{16} \mathrm{H}_{18} \mathrm{ClN}_{3} \mathrm{~S}\right.$, MW $=319.852 \mathrm{~g} / \mathrm{mol})$, was chosen as the model pollutants to evaluate the catalytic activity of the as-synthesized catalyst (Fig. 1). During the degradation process, $10 \mathrm{mg}$ of the catalyst was suspended in $50 \mathrm{~mL}$ of the MB $(10 \mathrm{mg} / \mathrm{L})$ aqueous solution. The MB color removal was evaluated by measuring the absorbance decrease at $664 \mathrm{~nm}$ by using an UV-visibe spectrometer apparatus (2300-Techcomp). The suspension was initially stirred for $10 \mathrm{~min}$ to disperse the catalyst; $10 \mathrm{~mL}$ of aqueous $\mathrm{NaOCl}$ $(12 \%)$ was added to the reaction mixture and allowed to react at room temperature. Each analysis point reported in this study was an average of at least three independent parallel sample solutions. The standard deviation of the results was $\pm 3 \%$.<smiles>CN(C)c1ccc2nc3ccc(N(C)C)cc3[s+]c2c1</smiles>

Fig. 1. Molecular structure of methylene blue

\section{RESULTS AND DISCUSSION}

\subsection{Structure and Morphology}

The X-ray diffraction pattern of the $\mathrm{CuO}$ samples prepared in the presence of SDS and $\mathrm{ClO}^{-} / \mathrm{OH}^{-}$ combination is depicted in Fig. 2. It can be clearly seen that all diffraction peaks can be indexed in the $\mathrm{CuO}$ monoclinic phase [24]. The obtained parameters were $(a=4.653 \AA, b=$ $3.410 \AA$ and $c=5.108 \AA$ with volume cell of $79.94 \AA^{3}$ ) consistent with the standard values for bulk CuO (JCPDS 05-0661). No peak from impurities can be observed in the XRD spectrum of the obtained sample, indicating high purity of $\mathrm{CuO}$ products. The broadening of the peaks indicates the small size of the product. The crystallite size (Table 1) was also calculated by X-ray line broadening analysis using the DebyeScherrer formula [25]. We found that the average $\mathrm{CuO}$ crystallite size was $22.3 \mathrm{~nm}$. After the five cycle of the $\mathrm{CuO}$ catalyst (Fig. 2b), we observed a slight decrease of the average crystallite size to $\sim 19 \mathrm{~nm}$ (Table 1).

Fig. 3 shows the nitrogen adsorption-desorption isotherm of the prepared $\mathrm{CuO}$, which was type II according to BDDT classification [26,27]. The pore volume and pore size distribution were obtained using the Barrett, Joyner and Halenda (BJH) method from desorption branch of the isotherms [28]. It was found that structured $\mathrm{CuO}$ possessed $144.473 \mathrm{~m}^{2} / \mathrm{g}$ of BET surface area, $0.092 \mathrm{cc} / \mathrm{g}$ pore volume and $5.619 \mathrm{~nm}$ Pore Diameter.

Table 1. Average crystallite size of CuO Nst calculated by the Scherrer's formula for the intense peak

\begin{tabular}{llll}
\hline (hkl) & $\begin{array}{l}\text { 2 } \theta \text { of the intense peak } \\
\text { (deg) }\end{array}$ & $\begin{array}{l}\text { HWFM of intense peak } \boldsymbol{\beta} \\
\left.\mathbf{(}^{\circ}\right) \text { before/after }\end{array}$ & $\begin{array}{l}\text { Size of the particle } \mathbf{D}(\mathbf{n m}) \\
\text { before/after }\end{array}$ \\
\hline$(-111)$ & 35,60 & $0.6298 / 0.3936$ & $23.61 / 21$ \\
$(111)$ & 39,02 & $0.3936 / 0.4723$ & $21 / 17.48$ \\
\hline
\end{tabular}




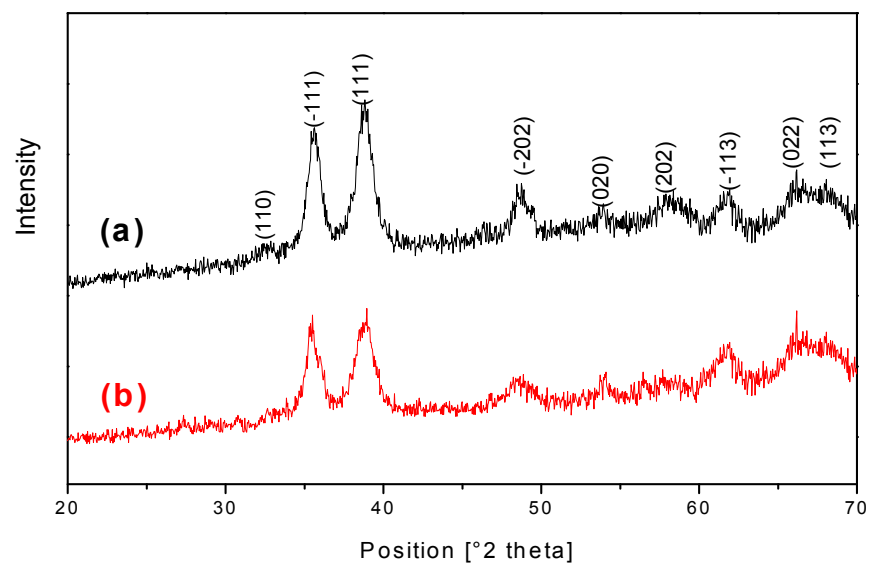

Fig. 2. XRD patterns of polycrystalline CuO (a) before and (b) after recycling.

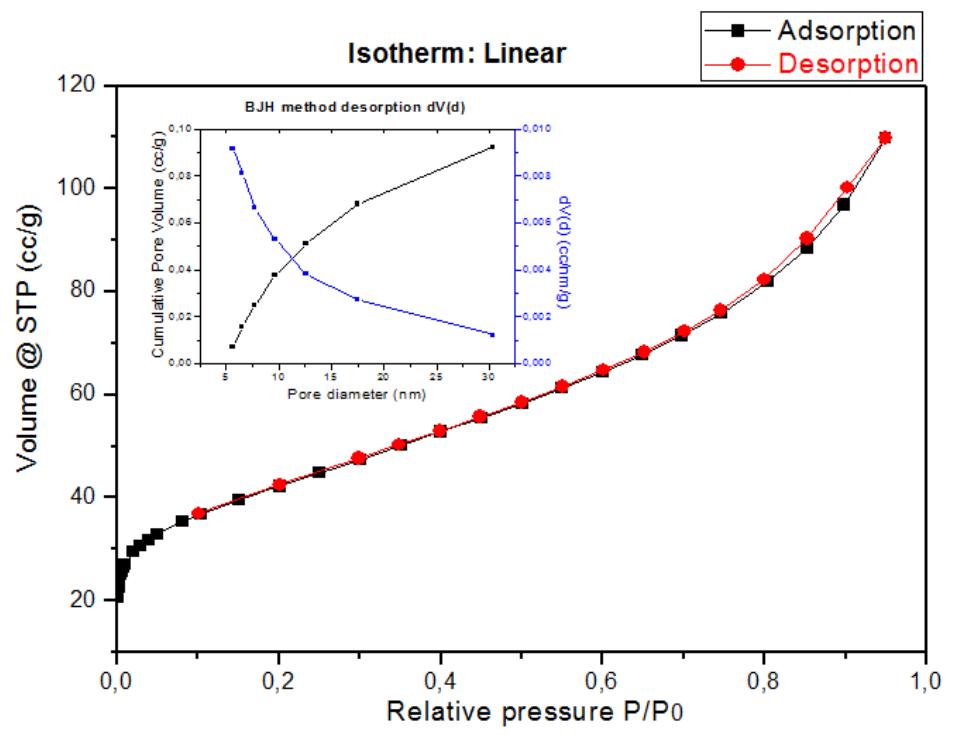

Fig. 3. $\mathrm{N}_{2}$ adsorption isotherm of the prepared $\mathrm{CuO}$

The morphology of the as-prepared $\mathrm{CuO}$ nanostructures is presented with TEM panoramic image in Fig. 4. Interestingly, the product consisted of ultrafine crystallites. Closer observation revealed that these ultrafine nanostructure materials were composed of nanowires. Most of the nanowires are densely to form compact nanowire arrays (Fig. 4a). Careful scaling of $\mathrm{CuO}$ nanowires reveals that they are 3-7 $\mathrm{nm}$ in diameter and about 8-30 $\mathrm{nm}$ in length. In order to provide further insight into the atomic structure of the prepared $\mathrm{CuO}$ nanowires, we have performed HR-TEM measurements. Fig. 4(b) reveals that the synthesized $\mathrm{CuO}$ product consists of highly ordered nanowires.
Concerning the synthetic mechanism of $\mathrm{CuO}$, we can show an indirect evidence that the $\mathrm{NaOCl}$ had an important effect in this synthesis by the transformation of $\mathrm{Cu}(\mathrm{OH})_{2}$ to $\mathrm{CuO}$. It's noteworthy that at room temperature and without $\mathrm{NaOCl}$, the reaction leads to the formation of $\mathrm{Cu}(\mathrm{OH})_{2}$. In the same conditions, the preparation of $\mathrm{CuO}$ needs high temperature $[8,13,15,19]$. Hence the presence of $\mathrm{NaOCl}$ facilitates the synthesis of $\mathrm{CuO}$ at room temperature. The same results are obtained by Viñals et al. [29] who reported that leaching of enargite $\left(\mathrm{Cu}_{3} \mathrm{AsS}_{4}\right)$ in the presence of $\mathrm{ClO}^{-} / \mathrm{OH}^{-}$ gave crystalline $\mathrm{CuO}$. 


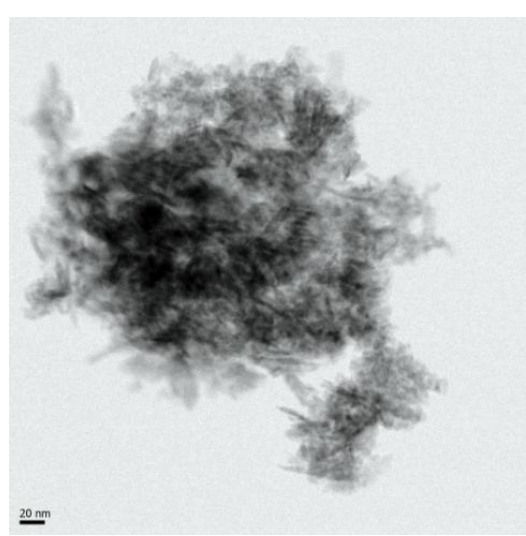

(a)

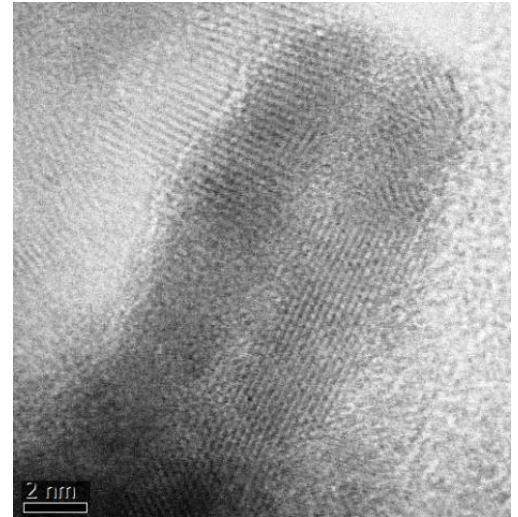

(b)

Fig. 4. (a) TEM image showing a cluster of CuO nanowire, (b) TEM image showing a highly oriented crystalline $\mathrm{CuO}$ nanowire

\subsection{Evaluation of the Catalyst in the Oxidative Degradation of Methylene Blue}

To explore the potential capability of the obtained $\mathrm{CuO}$ Nst to remove contaminants from wastewater, the catalytic activity was evaluated in the oxidation of $\mathrm{MB}$ in the presence of $\mathrm{NaOCl}$. Experiments were carried out both in the presence and in the absence of catalyst. In the absence of $\mathrm{NaOCl}$, no considerable degradation of MB took place after $60 \mathrm{~min}$.

During the course of the degradation, the color of MB solution became less intense, and the characteristic absorption of MB decreased gradually with the evolution of the reaction, due to the oxidation of $\mathrm{MB}$ in the presence of $\mathrm{CuO}$. Fig. 5 shows UV-vis absorption spectra of aqueous solution of $\mathrm{MB}$ in the presence of $\mathrm{CuO}$ and $\mathrm{NaOCl}$ at different reaction times. The intensity of the band at $664 \mathrm{~nm}$ decreases with the time during the catalytic oxidation without occurrence of new absorbance maxima. After $30 \mathrm{~min}, 93 \%$ of MB removal was occurred. In addition, the shift of the absorbance maximum to shorter wavelengths (hypsochromic effect) is not observed, which shows that $\mathrm{N}$-demethylation of MB auxochromic groups does not take place during the catalytic oxidation. A similar effect was observed by other authors studying the photocatalytic oxidation of MB [30].

Therefore, for the evaluation of the reaction rate, pseudo-first order kinetics with respect to MB is a reasonable assumption. Because the ratio of the absorbance $A_{t}$ of $M B$ at time=t to its initial value $A_{0}$ measured at $t=0$ equals the concentration ratio $C_{t} / C_{0}$ of $M B$, the reaction rate constant $(k)$ for the first order reaction is $\ln \left(A_{t} / A_{0}\right)$ $=\mathrm{kt}$.

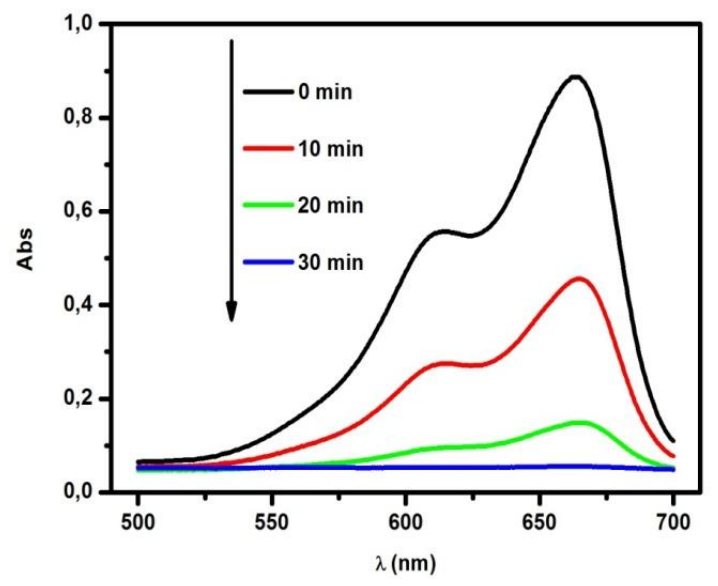

Fig. 5. UV-visible spectra obtained during the MB oxidative degradation in the presence of CuO Nst

As depicted in Fig. 6, the evolution of $\operatorname{Ln}\left(\mathrm{C}_{0} / \mathrm{C}\right)$ versus time shows a linear relationship $\left(R^{2}=\right.$ 0.99), indicating clearly that the oxidative degradation of the dye follows a pseudo first order kinetics. The rate constant $k$ was calculated from the slope of the line and a value of $0.10643 \mathrm{~min}^{-1}$ was obtained.

In order to study the effect of the catalyst on the degradation of $\mathrm{MB}$, discoloration experiments were carried out at different amounts of catalyst $(5,8,10,15 \mathrm{mg})$, and the corresponding results are given in Table 2 . The discoloration rate 
increased with increasing the catalyst amount to 8-10 mg. However, exceeding the optimum amount of catalyst amount (8-10 mg), have a negative effect on the degradation efficiency (Table 2, entries 1, 2, 3 and 6). It can be concluded that the higher loading of the catalyst may not be useful in view of the aggregation [31,32].

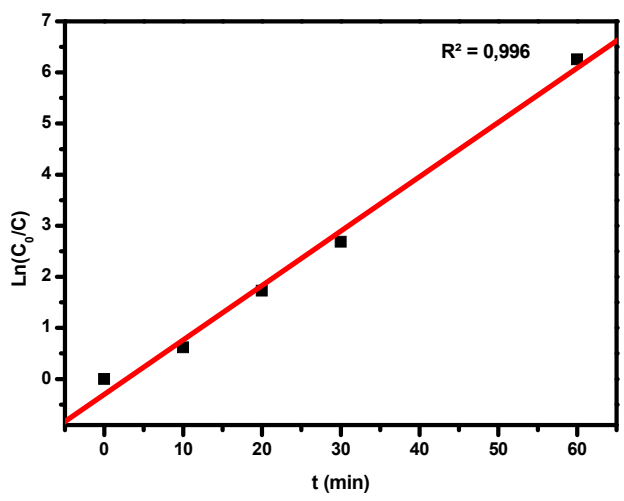

Fig. 6. Plot of $\ln \left(C_{t} / C_{0}\right)$ versus time for the oxidation of MB by CuO Nst

The effect of initial concentration of $M B$ on catalytic activity of $\mathrm{CuO}$ Nst was studied by varying the initial dye concentration from 10 to $30 \mathrm{mg} / \mathrm{L}$ (Table 2). It seems that the degradation efficiency is not significantly dependent on the initial dye concentration. The results in Table 2 show that dye degradation efficiency decreases slowly as the concentration of MB increased (Table 2, entries 3, 4 and 5). The decrease of catalytic activity can be explained by the saturation of the catalyst surface by dye molecules reducing the contact with $\mathrm{NaOCl}$ molecules.
In the other hand, increasing volume of $\mathrm{NaOCl}$ solution lead to decrease of the degradation efficiency when exceeding the volume of $10 \mathrm{~mL}$ (Table 2, entries 3, 7, 8 and 9). The results regrouped in Table 2 showed that $10 \mathrm{~mL}$ of $\mathrm{NaOCl}$ solution (12\%) was the optimum volume.

\subsection{Recycling Catalyst}

After demonstrating the high catalytic activity of the prepared $\mathrm{CuO}$ Nst and in order to delineate the scope and limitation of the procedure described above, the reusability of the catalyst was checked. Hence, the catalyst was recovered for successive degradation of MB showing good catalytic activity (Table 3 ). The catalyst was separated by filtration, washed with water, ethanol and acetone and dried at $100^{\circ} \mathrm{C}$ overnight before reuse. As it can be seen in Table 3, the yields of MB degradation after 60 min were still very good after five run.

These results showed that the catalyst can be reused more than five cycles without any decrease in activity. The high catalytic activity of reused $\mathrm{CuO}$ Nst is visualized by the nearly unalterable crystallite size of $\mathrm{CuO}$ (Nst) during the five cycles (Fig. 2, Table 1) and no agglomeration of nanowires in the reaction medium, acting positively on the substratecatalyst contact surface. Furthermore, X-ray fluorescence study of aqueous reaction mixture after filtration shows that there is no trace of copper found in the solution. All these results conclude that as-prepared $\mathrm{CuO}$ Nst could work as an effective and reusable heterogeneous catalyst and the reaction occurs in the surface of nanowire without any leaching of metal species.

Table 2. Effect of the amount of $\mathrm{CuO}$, volume of $\mathrm{NaOCl}$ solution and concentration of $\mathrm{MB}$ on the degradation of MB catalyzed by CuO Nst

\begin{tabular}{|c|c|c|c|c|c|}
\hline \multirow[t]{2}{*}{ Entries } & \multirow[t]{2}{*}{$\mathrm{CuO}$ (mg) } & \multirow[t]{2}{*}{ MB (mg/L) } & \multirow[t]{2}{*}{$\mathrm{NaOCl}(\mathrm{mL})$} & \multicolumn{2}{|c|}{$\%$ MB degradation } \\
\hline & & & & $30 \mathrm{~min}$ & $60 \mathrm{~min}$ \\
\hline 1 & 5 & 10 & 10 & 83.9 & 100 \\
\hline 2 & 8 & 10 & 10 & 93.69 & 100 \\
\hline 3 & 10 & 10 & 10 & 93.67 & 100 \\
\hline 4 & 10 & 20 & 10 & 92.56 & 99.79 \\
\hline 5 & 10 & 30 & 10 & 91.61 & 99.36 \\
\hline 6 & 15 & 10 & 10 & 86.23 & 98.83 \\
\hline 7 & 10 & 10 & 05 & 91.37 & 99,08 \\
\hline 8 & 10 & 10 & 15 & 88.15 & 98.39 \\
\hline 9 & 10 & 10 & 20 & 74.11 & 98.27 \\
\hline
\end{tabular}


Table 3. Degradation of MB catalyzed by CuO Nst: catalyst recyclability

\begin{tabular}{llllll}
\hline $\mathbf{N}^{\circ}$ of cycle & $\mathbf{1}$ & $\mathbf{2}$ & $\mathbf{3}$ & $\mathbf{4}$ & $\mathbf{5}$ \\
\hline$\%$ MB degradation & 95.08 & 96.17 & 96.37 & 95.32 & 96,16 \\
\hline \multicolumn{6}{c}{ Conditions: reaction time: $60 \mathrm{~min}, \mathrm{CuO}(10 \mathrm{mg}),[\mathrm{MB}]=10$} \\
\hline
\end{tabular}

\section{CONCLUSION}

Nanostructured $\mathrm{CuO}$ with high surface area and uniform pore size distribution has been prepared by simple and inexpensive room temperature solution method. The synthesized $\mathrm{CuO}$ product consists of highly ordered nanowires with 3-7 $\mathrm{nm}$ in diameter and about 8-30 $\mathrm{nm}$ in length. It is a promising candidate for potential application in catalysis. We have shown that it can be used as efficient catalyst for the degradation of methylene blue in the presence of commercially available sodium hypochlorite. Moreover, the $\mathrm{CuO}$ Nst could be re-used at least five times maintaining an excellent activity.

\section{COMPETING INTERESTS}

Authors have declared that no competing interests exist.

\section{REFERENCES}

1. Akrout $H$, Jellali $S$, Bousselmi $L$. Enhancement of methylene blue removal by anodic oxidation using BDD electrode combined with adsorption onto sawdust. C R Chimie. 2015;18:110-120.

2. Junejo $Y$, Sirajuddin, Baykal A, Ssfdar M, Balouch A. A novel green synthesis and characterization of Ag NPs with its ultrarapid catalytic reduction of methyl green dye. Appl Surf Sci, 2014;290:499-503.

3. Sohrabnezhad SH. Study of catalytic reduction and photodegradation of methylene blue by heterogeneous catalyst. Spectrochim Acta Part A. 2011;81:228-235.

4. Lin SH, Peng CF. Treatment of textile wastewater by electrochemical method. Water Research. 1994;28:277-282.

5. Cooper $\mathrm{P}$, Removing color from dye house waste waters, a critical review of technology available. J Soc Dyers Colourists. 1993;109:97-100.

6. Chan PY, Gamal EDM, Bolton JR. A solar-driven UV/chlorine advanced oxidation process, Water Res. 2012;46:5672-5682.

7. Liao J, Li H, Zhang X, Xiao D, Qiang N. Facile fabrication of $\mathrm{Ti}$ supported $\mathrm{CuO}$ film composed of bamboo-leaf-like nanosheets and their high catalytic performance in the oxidative degradation of methylene blue with hydrogen peroxide. Applied Catalysis A: General. 2015;491:94-99.

8. Zhong Z, Ng V, Luo J,Teh Sp, Teo J, Gedanken A. Manipulating the Selfassembling process to obtain control over the morphologies of copper oxide in hydrothermal synthesis and creating pores in the oxide architecture. Langmuir. 2007; 23(11):5971-77.

9. Faisal M, Khan Sb, Rahman Mm, Jamal A, Umar A. Ethanol chemi-sensor: Evaluation of structural, optical and sensing properties of $\mathrm{CuO}$ nanosheets. Mater. Lett. 2011;65(9):1400-03.

10. Liu Y, Liao L, Li J, Pan C. From copper nanocrystalline to cuo nanoneedle array: Synthesis, growth mechanism, and properties. J. Phys. Chem. C. 2007; 111(13):5050-56.

11. Zhang W, Wen X, Yang S. Controlled reactions on a copper surface: Synthesis and characterization of nanostructured copper compound films. Inorg Chem. 2003;42(16):5005-14.

12. Cao M, Hu C, Wang Y, Guo Y, Guo C, Wang E. A controllable synthetic route to $\mathrm{Cu}, \mathrm{Cu}_{2} \mathrm{O}$ and $\mathrm{CuO}$ nanotubes and nanorods. Chem Commun. 2003;15:188485.

13. Liang ZH, Zhu YJ. Microwave-assisted synthesis of single-crystalline $\mathrm{CuO}$ nanoleaves. Chem. Lett. 2004;33(10): 1314-15.

14. $\mathrm{Yu}$ Y, Zhang J. Solution phase synthesis of rose like CuO. Mater. Lett. 2009;63: 1840-43.

15. Yuvaraj $\mathrm{H}$, Jae-Jin S. Facile synthesis of $\mathrm{CuO}$ nanospindles from a 3D coordination complex and its application to nanofluids. Materials Letters. 2014;116:5-8. b) Xiling L, Wenfeng G, Hui $H$, Tingfang $C$, Moyu $Z$, Yinshu W. Synthesis and photocatalytic properties of $\mathrm{CuO}$ nanostructures. Journal of Nanoscience and Nanotechnology. 2014;14:3428-32.

16. Su Y, Shen C, Yang H, Li H, Gao H. Controlled synthesis of highly ordered $\mathrm{CuO}$ nanowire arrays by template-based 
sol-gel route. Trans Nonferrous Met Soc China. 2007;17:783-86.

17. Pendashteh A, Rahmanifar MS, Mousavi M. Morphologically controlled preparation of $\mathrm{CuO}$ nanostructures under ultrasound irradiation and their evaluation as pseudocapacitor materials. Ultrasonics Sonochemistry. 2014;21:643-652

18. Chao $Y$, Feng $X$, Jide W, Xintai $S$. Synthesis and microwave modification of CuO nanoparticles: Crystallinity and morphological variations, catalysis, and gas sensing. Journal of Colloid and Interface Science. 2014;435:34-42.

19. Tingting $J$, Yongqian $W$, Dawei $M$, Xiuling $W$, Junxia $W$, Jieyu C. Controllable fabrication of $\mathrm{CuO}$ nanostructure by hydrothermal method and its properties. Applied Surface Science. 2014;311:602-608

20. Dan R. Clary, G. Mills. Preparation and thermal properties of $\mathrm{CuO}$ particles. Journal of Physical chemistry. 2011;115: 1767-1775.

21. Chiang C, Aroh K, Ehrman H. Copper oxide nanoparticle made by flame spray pyrolysis for photoelectrochemical water splitting Part I. CuO nanoparticle preparation, Int. J Hydrogen Energ. 2012; 37(6):4871-79.

22. Borgohain K, Singh J, Rama M, Shripathi T, Mahamuni S. Quantum size effects in CuO nanoparticles. Phys. Rev. B. 2000; 61:11093-96.

23. Zheng X, Xu C, Nishikubo K, Nishiyama K, Higemoto W, Moon W, Tanaka E, Otabe E. Phy Rev B. 2006;72:14464-68.

24. Hanawalt JD, Rinn $\mathrm{WH}$, Frevel $\mathrm{KL}$. Chemical analysis by X-ray diffraction Classification and use of $x$-ray diffraction patterns. Anal Chem. 1938;10:475-512.
25. Scherrer P. Bestimmung der Größe und der inneren Struktur von Kolloidteilchen mittels Röntgenstrahlen, Göttinger Nachrichten. Gesell. 1918;2:98-100.

26. Zhang $\mathrm{H}$, Zhang $\mathrm{Y}$, Li C. Enantioselective epoxidation of olefins catalyzed by the $\mathrm{Mn}$ (salen) catalysts immobilized in the nanopores of mesoporous materials. J Catal. 2006;238(2):369-81.

27. Blin JL, Flamant R, Su B. Synthesis of nanostructured mesoporous zirconia using CTMABr-ZrOCl $2.8 \mathrm{H}_{2} \mathrm{O}$ systems: a kinetic study of synthesis mechanism. Inter $\mathrm{J}$ Inorg Mater. 2001;3(7):959-72.

28. Brunauer S, Deming L, Deming W, Teller E. On a theory of the van der Waals adsorption of gases. J Am Chem Soc. 1940;62(7):1723-32.

29. Viñalsa J, Rocaa A, Herna'ndezb MC, Benaventea O. Topochemical transformation of enargite into copper oxide by hypochlorite leaching. Hydrometallurgy. 2003;68:183-193.

30. Zhang T, Oyama T, Aoshima A, Hidaka H, Zhao J, Serpone N. Photooxidative Ndemethylation of methylene blue in aqueous $\mathrm{TiO} 2$ dispersions under UV irradiation. J Photochem. Photobiol. A: Chem. 2001;140(2):163-72.

31. Nezamzadeh-Ejhieh A, Zabihi-Mobarakeh $\mathrm{H}$, Heterogeneous photodecolorization of mixture of methylene blue and bromophenol blue using CuO-nanoclinoptilolite. J Ind Eng Chem. 2014;20: 1421-1431.

32. Nezamzadeh-Eghieh A, Khorsandi M. A comparison between the heterogeneous photodecolorization of anazo dye using $\mathrm{Ni} / \mathrm{P}$ zeolite and NiS/P zeolite catalysts. Iranian J Catal. 2011;2:99-104.

(c) 2015 El Farrouji et al.; This is an Open Access article distributed under the terms of the Creative Commons Attribution License (http://creativecommons.org/licenses/by/4.0), which permits unrestricted use, distribution, and reproduction in any medium, provided the original work is properly cited.

\section{Peer-review history:}

The peer review history for this paper can be accessed here: http://www.sciencedomain.org/review-history.php?iid=1052\&id=7\&aid=9548 